\title{
VIAGEM AO PAÍS DAS MIRAÇÕES: EM BUSCA DA CONTRACULTURA NOS ANOS 80 NO BRASIL
}

\author{
CARVALHO, César Augusto de \\ Viagem ao mundo alternativo: a contracultura nos anos 80 . \\ São Paulo: Editora da Unesp, 2008 [no prelo].
}

\section{POR}

\section{Carolina Branco de Castro Ferreira ${ }^{1}$}

$\mathrm{N}$ 0 ano de 2008, uma série de lançamentos e reedições de livros, cadernos especiais em jornais, edições de revistas acadêmicas e debates em francês como referência histórica que influenciou comportamentos de diversas naturezas, teorias, valores, concepções e acontecimentos políticos. No Brasil, esta data tem como referência principal a resistência estudantil ao regime militar.

$\mathrm{Na}$ edição especial 1968-2008 do Caderno 2 do Jornal O Estado de São Paulo, Slavoj Zizek (2008) ${ }^{2}$ argumenta que o que sobreviveu da libertação sexual dos anos 1960 foi um "hedonismo tolerante, facilmente incorporado a nossa ideologia hegemônica: hoje o prazer sexual não é apenas permitido, é ordenado”. Segundo o autor, os modos radicais de prazer, sejam pelas experiências sexuais

\footnotetext{
${ }^{1}$ Antropóloga, doutoranda do programa em Ciências Sociais da Universidade Estadual de Campinas.

${ }^{2}$ Jornal 0 Estado de S. Paulo, Caderno 2 - Cultura, domingo, 11 de maio de 2008.
} 
ou com drogas, sejam por outros meios de indução ao transe, surgiram quando 0 "espírito de 68" esgotou seus potenciais políticos.

A alternativa que restou nos anos 70 foi "um direto e brutal empurrão para 0 real", um recuo do engajamento sócio-político concreto para o contato direto com o real que, segundo o autor, assumiu três formas principais: a busca ao extremo por prazer sexual, o terrorismo político de esquerda e a opção pelo real de uma experiência interior.

É esta última questão que está problematizada no livro Viagem ao mundo alternativo: a contracultura nos anos 80, de César Augusto de Carvalho. No início da década de 80, o autor, interessado em desenvolver uma pesquisa sobre os paradigmas do conhecimento e problematizar possíveis alternativas que estivessem fora da lógica racional da ciência nas sociedades modernas ocidentais, busca respostas ao tomar as comunidades alternativas brasileiras como objetos de estudo.

Nesta época, a mídia noticiava o fato de jovens estarem indo morar em lugares distantes das grandes metrópoles com a proposta de criarem tais comunidades, na busca de maneiras comunitárias de viver, na recusa da sociedade de consumo, na crítica à ciência ocidental e, principalmente, na luta pela defesa da natureza.

A pesquisa do autor foi realizada em dois momentos. 0 primeiro, em 1984, quando de sua estadia na região Sul de Minas Gerais - São Lourenço, um dos principais pólos ecológicos, o permitiu participar do Encontro Nacional de Comunidades Alternativas (ENCA), realizado em Pindamonhangaba. E o segundo momento, realizado em 1986, a partir de uma viagem que abrangia mais de oito estados brasileiros nos quais se localizavam pólos eniergéticos, isto é, lugares considerados pelo movimento alternativo como portais místicos que concentrariam um fluxo eletromagnético que permitiriam às pessoas contatos de diversos tipos, tais como com extraterrestres, com o mundo espiritual, dentre outros.

Paratraçaro roteiro daviagem, CésarCarvalho contou como auxiliodo Guia do Peregrino, publicação que trazia informações sobre as principais comunidades daquele tipo no Brasil. Antes de partir para a viagem, enviou correspondências aos lugares indicados pelo guia; como não obteve resposta, não hesitou: caiu na estrada com sua moto, uma CG 125, em direção às comunidades. 
0 livro está divido em capítulos que trazem as histórias dos lugares, as experiências pessoais do autor durante a viagem, as entrevistas e narrativas de pessoas envolvidas com o movimento alternativo em Campo Grande, Rondonópolis, Cuiabá, Chapada dos Guimarães, Porto Velho, Rio Branco, Chapada dos Viadeiros, Porto Seguro e outros. 0 autor definiu seu empreendimento como viagemdocumento na qual coletou os dados empíricos e entrevistas, e como viagem mítica, uma vez que a pesquisa lhe permitiu redimensionar simbolicamente sua vida, sua profissão, a relação sujeito-objeto, os paradigmas do conhecimento e, no limite, seu próprio objeto de pesquisa.

Apesar da definição metodológica de seu estudo como viagem-documento e viagem mítica, ao ler eu pensava: isso é uma bela etnografia! 0 leitor encontrará descrições minuciosas da viagem, das paisagens, das comidas, das vestimentas e das práticas dos sujeitos do circuito alternativo brasileiro dessa época. Mais do que as descrições densas que definem a etnografia, na escrita do autor está presente uma discussão contemporânea sobre o fazer etnográfico e sobre a relação sujeitoobjeto.

A pesquisa de campo não se refere apenas a um conjunto de técnicas para coleta de dados, mas implica uma relação social entre o pesquisador e os sujeitos pesquisados, e a qualidade daqueles depende, em grande parte, da maneira como essa interação se estabelece. A partir dos anos 1960, formularam-se críticas às etnografias clássicas, nas quais o autor se encontraria ausente ao longo do texto ou, quando muito, descreveria brevemente o modo como chegou ao grupo estudado e a sua convivência com ele, a fim de legitimar os dados que apresenta.

Em suma, esse é um longo e espinhoso debate. No entanto, o que importa aqui é lembrar que as contribuições trazidas à escrita do texto acadêmico pelas teorias "pós-modernas" não devem ser confundidas com a autobiografia do autor, porque se trata de fazer, tanto do texto/etnografia quanto da autobiografia daquele, elementos de reflexão que possibilitem compreender a proximidade e a distância social que o une e o separa do grupo que ele observa e estuda, sejam eles pertencentes à mesma sociedade ou não.

A narrativa de Carvalho traz essa contribuição. 0 texto escrito em primeira pessoa não esconde os "problemas" e aflições, tanto de ordem prática, subjetiva, conceitual e teórica que estiveram presentes no decorrer da pesquisa. Os longos trechos das conversas com os sujeitos das pesquisas, os relatos que vão desde os banhos de cachoeira na Chapada dos Guimarães às suas experiências com o Daime 
no norte do país nos falam de seus medos, angústias, preconceitos e descobertas a respeito dos sentidos da existência humana e de sua busca pelo entendimento da subjetividade contracultural. Assim, para entendê-la, foi fundamental tomá-la como experiência, pois aquela parece se apoiar em linguagens e elementos mais sensíveis do que intelectuais.

0 autor afirma que a escolha por relatar a viagem, mais que uma opção estética, foi também uma opção metodológica, e esta não pode ser definida $a$ priori. Ao iniciar sua busca pelas comunidades, o autor se deu conta que elas não existiam da maneira como ele havia idealizado. Advertido por Heitor, um dos sujeitos de sua pesquisa, de que o movimento alternativo não existia como a "imagem que está formada em sua mente", o autor se pôs a reelaborar seu objeto de pesquisa.

Nesse sentido, "o movimento alternativo não era um movimento de comunidades, mas de pessoas ligadas a um universo simbólico fundamentado na restauração e preservação do homem e da natureza" (p.134), e seu caráter mítico vinha da possibilidade de ressignificar a vida humana passando pelo reencontro com o espírito pela ligação cósmica ou pela religião.

Como uma rede que opera a partir de um bricoleur de práticas e dietas naturalistas, princípios místicos variados e uso ritualístico de drogas (às vezes nem tão ritualísticos assim...) é que se configura um estilo de vida. Segundo o autor, a proposta hedonista dos 60 foi substituída por práticas voltadas para a criação de modelos alternativos à sociedade vigente. Assim, mais do que a Grande Recusa de Marcuse, para Carvalho o movimento alternativo buscava uma inserção no sistema. Nesse sentido, mais do que as comunidades, era importante a manutenção das condições alternativas de vida que para promover projetos de recuperação e preservação ecológica.

A partir da reflexão de músicas, filmes e livros ligados a padrões de comportamentos dos beats e bippies que marcaram as décadas de 50, 60 e 70 nos Estados Unidos e na Europa, o início do movimento contracultural, na década de 70 no Brasil, e sua experiência de pesquisa, o autor faz uma avaliação do papel da mídia neste fenômeno:

0 profundo grito de recusa ao mal estar civilizacional, dado pela inquieta juventude dos anos 50 e 60 , ganhou projeção na complexa rede de comunicação que se crivava em termos globais. Nos anos 80 , a rebeldia era menos radical, mas o papel da mídia se repetia. Neste processo interativo 
produziu-se uma simbiose: de um lado, os jovens alimentavam o novo sistema de comunicação, por outro eram alimentados e incentivados pelo mesmo sistema (p. 283).

Assim, segundo o autor, a contracultura é um fenômeno global e midiático, sua historicidade está entrelaçada na nova comunicação global. A história da contracultura tem sido a busca por uma consciência capaz de resolver conflitos internos a partir de um processo de individuação. 0 efeito desta busca é a propagação de alternativas filosóficas, religiosas, estéticas e sociais que acabam se estabelecendo como alternativas disponíveis no mercado. Contudo, há algo nesta experiência contracultural que nem o mercado, nem o sistema capitalista conseguem capturar: a experiência mítica que o sujeito individual desenvolveu e que "não é intercambiável, independentemente das condições históricas dadas" (p. 284). Resta saber se essa experiência é suficiente para gerar processos de mudança e engajamentos sociopolíticos mais amplos. Ao ler este livro, parece que não.

No final do livro, César Carvalho relata o término de sua viagem e uma conversa com um velho amigo, na qual expõe suas dúvidas sobre como organizar os dados e experiências da pesquisa: escreveria um romance? Como se chamaria? Talvez, viagem ao país das mirações? Não. Desta maneira seria impossível resolver os problemas que o motivaram a viajar; eles teriam que ser encarados no campo do conhecimento científico. Este campo conta hoje com uma importante contribuição, e mesmo não sendo um romance, é uma leitura muito agradável. 